\title{
The role of sleep in bipolar disorder
}

Nature and Science of Sleep

29 June 2016

Number of times this article has been viewed

\section{Alexandra K Gold' \\ Louisa G Sylvia ${ }^{1,2}$}

'Department of Psychiatry, Massachusetts General Hospital, ${ }^{2}$ Harvard Medical School, Boston, MA, USA

Correspondence: Alexandra K Gold

Department of Psychiatry, Massachusetts

General Hospital, 50 Staniford Street,

Suite 580, Boston, MA 02II4, USA

Tel + I 6176436194

Fax + | 6177266768

Email alexandrakategold@gmail.com
Abstract: Bipolar disorder is a serious mental illness characterized by alternating periods of elevated and depressed mood. Sleep disturbances in bipolar disorder are present during all stages of the condition and exert a negative impact on overall course, quality of life, and treatment outcomes. We examine the partnership between circadian system (process $\mathrm{C}$ ) functioning and sleep-wake homeostasis (process S) on optimal sleep functioning and explore the role of disruptions in both systems on sleep disturbances in bipolar disorder. A convergence of evidence suggests that sleep problems in bipolar disorder result from dysregulation across both process $\mathrm{C}$ and process $\mathrm{S}$ systems. Biomarkers of depressive episodes include heightened fragmentation of rapid eye movement (REM) sleep, reduced REM latency, increased REM density, and a greater percentage of awakenings, while biomarkers of manic episodes include reduced REM latency, greater percentage of stage I sleep, increased REM density, discontinuous sleep patterns, shortened total sleep time, and a greater time awake in bed. These findings highlight the importance of targeting novel treatments for sleep disturbance in bipolar disorder.

Keywords: bipolar disorder, circadian rhythms, sleep-wake homeostasis

\section{Introduction}

\section{Bipolar disorder: a background}

Bipolar disorder, a severe and chronic mental illness with a lifetime prevalence of $\sim 1.0 \%,{ }^{1}$ is characterized by alternating episodes of depressed and elevated mood. ${ }^{2}$ Regarded as the sixth leading cause of disability internationally, ${ }^{3}$ bipolar disorder is associated with standard mortality rates ranging from 1.9 to $2.1,{ }^{4}$ resulting from cardiovascular disease (CVD), diabetes mellitus, pneumonia, influenza, chronic pulmonary obstructive disease, and suicide, among other factors. ${ }^{5}$ Research indicates that $>50 \%$ of bipolar patients experience one or more medical comorbidities associated with poor health behaviors (eg, physical inactivity and cigarette smoking), side effects from pharmacological treatments (eg, weight gain), and nonadherence to established treatment regimens. ${ }^{6}$ Many bipolar patients also suffer from comorbid psychiatric conditions such as anxiety disorders and substance-use disorders. ${ }^{1,7}$ In addition to increasing mortality risk, such comorbidities result in reduced quality of life and overall poor mental health, thus contributing to continued mood symptoms and a worsened course of bipolar illness. ${ }^{1,4,6,8}$

Bipolar disorder is largely considered in terms of two diagnostic subtypes that vary with regard to mood episode characteristics, presentation, and episode severity. The first subtype, bipolar I disorder, is marked by one or more lifetime episodes of mania or a 
continuously elevated or irritable mood. Episodes of mania are characterized by at least 1 week of specific symptoms such as perceptions of grandiosity, increased flight of ideas, racing thoughts, increased talkative behaviors, reduced need for sleep, impulsive behaviors, distractibility, and heightened risk-taking that impairs one's ability to function. ${ }^{2}$ Many patients with bipolar I disorder also experience periods of depressed mood. Bipolar II disorder is characterized by one or more episodes of hypomania or a period of elevated mood lasting for only 4 days and with fewer symptoms than mania and is not associated with any impairment. Patients with bipolar II disorder also have experienced at least one major depressive episode. ${ }^{2}$ Given that sleep disruptions are key symptoms of both the manic and depressive phases of bipolar I and II disorders, we chose to consider bipolar I and II together for the purposes of this manuscript.

\section{Bipolar disorder and sleep disturbances}

Sleep disturbances are highly prevalent among bipolar patients and exert a detrimental impact on course of illness, self-reported quality of life, functioning, symptom burden, and overall treatment outcomes. ${ }^{9-11}$ Sleep disturbances are often highly comorbid with other psychiatric conditions and maladaptive health behaviors such as substance-use disorders, ${ }^{12}$ anxiety disorders, ${ }^{13}$ increased weight and obesity, and lack of physical activity. ${ }^{12}$ Such sleep disturbances occur across all stages of the illness such as directly preceding a mood episode and during an acute mood episode (eg, a depressive, manic, or mixed episode). Further, sleep disturbances are not unique to symptomatic bipolar patients; studies have noted the presence of sleep problems in euthymic (or remitted) bipolar patients, ${ }^{9,14}$ highlighting the importance of sleep as a treatment target throughout all stages of the bipolar illness.

Sleep disturbances can manifest differently at various stages of the illness. During mania or hypomania, sleep disruptions are commonly presented as a reduced need for sleep with studies finding that $69 \%-99 \%$ of bipolar individuals report a lessened need for sleep during a manic episode or difficulties in falling and/or staying asleep. ${ }^{15}$ During depression, sleep disruptions are commonly exhibited as hypersomnia or excessive sleepiness. Hypersomnia is highly prevalent in bipolar disorder with rates ranging from $38 \%$ to $78 \%$ of bipolar patients. ${ }^{16}$ However, bipolar depression is also often characterized with severe insomnia. ${ }^{15}$ Importantly, this sleep disturbance is associated with worse course of illness. For example, sleep disturbances were cited as the most common prodrome for a manic episode. ${ }^{17,18}$ Studies have found the onset of sleep disturbances to predate the experience of the affective symptoms that characterize bipolar disorder. ${ }^{19}$

The high rates of sleep disturbance in individuals with bipolar disorder, its pervading presence across the subtypes and stages of this condition, and its deleterious impact on its course raise an important question: Why does sleep seem to be at the root of bipolar disorder? If we could answer this question, it may lead to answers in how to treat this complex and chronic condition more effectively. To that end, this manuscript investigates the mechanisms and pathways contributing to sleep disturbances in bipolar patients. Broadly, individuals with bipolar disorder may possess a certain genetic predisposition for sleep problems; this predisposition may subsequently contribute to an abnormal shift or dysregulation within the bipolar individual's circadian rhythm systems. ${ }^{9,20,21}$ This manuscript will examine the factors influencing sleep disturbances in bipolar disorder, biomarkers of sleep disturbances across various bipolar episodes, and the role of sleep disturbances in bipolar episode relapse.

\section{Circadian systems and sleep-wake homeostasis: an overview}

A widely accepted explanation for sleep disturbances in bipolar disorder rests on a circadian system model, which posits that sleep problems among bipolar patients result from dysregulated circadian rhythms. ${ }^{20}$ Circadian rhythms are biological processes that adopt an $\sim 24$-hour cycle or rhythm. ${ }^{21}$ Such biological processes include internal body temperature regulation, feeding activity, hormone secretion, the sleep-wake rhythm, and overall mood..$^{22}$ Rhythms are considered to be circadian if they occur without external cues or if they are endogenous (eg, originate internally). ${ }^{21}$ Thus, circadian rhythms are an innate system that allows the body to maintain the processes critical to survival, health, and overall functioning (eg, hormones, sleep, and temperature). ${ }^{21}$

Circadian rhythms are regulated via the suprachiasmatic nucleus ( $\mathrm{SCN}$ ) in the anterior hypothalamus above the optic chiasm. Commonly referred to as the "master clock" or the "master pacemaker", the SCN is responsible for overseeing circadian rhythms with assistance from several peripheral clocks in various cells, tissues, and organs..$^{20,23}$ Our internal clock is synchronized with the external world through zeitgebers, which are environmental cues that provide the necessary stimulus to entrain to the 24-hour light/dark cycle. ${ }^{21,24}$ The SCN, for instance, is highly sensitive to light, a photic zeitgeber. $^{20,23}$ Zeitgebers that are especially relevant to the peripheral clocks include eating schedules, social activities, and physical activity. As discussed further subsequently, 
failed synchronizing between these internal rhythms and external cues may be a key factor disrupting circadian systems, leading to mood episodes ${ }^{25}$ and sleep disruptions in bipolar patients. ${ }^{20,21,26}$

In healthy organisms, the neurobiological processes underlying circadian systems follow a characteristic pattern. Photic inputs (eg, light-related inputs) are transported from the retina to the $\mathrm{SCN}$ across the retinohypothalamic tract. The SCN projects to several hypothalamic nuclei and to a broad array of neural areas ${ }^{22}$ with the $\mathrm{SCN}$ also receiving nonphotic input from various brain regions. The SCN integrates the photic and nonphotic inputs to create a signal that helps maintain the organism's overall functioning (eg, body temperature and sleep-wake cycle). ${ }^{27}$ In addition, the SCN moderates the production of melatonin and cortisol, which are hormones that serve an important role in the timing of sleep and help maintain the sleep-wake cycle. ${ }^{28,29}$

The sleep-wake cycle is importantly regulated not only through a circadian system process (process $\mathrm{C}$ ) but also through the process of sleep-wake homeostasis (process S). This process ensures that the drive, or need, for sleep progressively increases with continued wakefulness such that, the longer that one has been awake, the greater the drive for sleep. The need for sleep typically is at its maximum in the evening (eg, bedtime). The converse also holds true; increased sleep is associated with a decreased need for sleep. Thus, sleep-wake homeostasis is an important process regulating sleep time and duration. Data suggest that adenosine, a neurotransmitter, serves an important role in sleep-wake homeostasis as adenosine levels rise during increased periods of wakefulness (resulting in an increased need for sleep) and fall during increased periods of sleep (resulting in a decreased need for sleep). ${ }^{30-35}$

\section{Circadian rhythm disruptions in bipolar disorder}

Recent research has determined that a nonadaptive circadian system is a biomarker of bipolar disorder. ${ }^{36}$ Specifically, individuals with bipolar disorder have weakly entrained circadian systems, which contribute to their mood episodes and impact their social rhythms such as sleep and meal timing. ${ }^{37}$ According to a circadian rhythm disruption model of bipolar disorder, abnormal circadian rhythms interact with various competing social zeitgebers, leading to mania (characterized by behavioral activation) or depression (characterized by behavioral inhibition). ${ }^{24,37}$ In one study, Malkoff-Schwartz et $\mathrm{al}^{38}$ found that life events that caused social rhythm disruptions were associated with the onset of manic episodes. ${ }^{37,38}$
Evidence of circadian rhythm disruptions has been cited in several studies of bipolar disorder. For example, in one study, euthymic bipolar patients had decreased melatonin secretion as well as a delayed peak time of melatonin at night compared to healthy control participants. ${ }^{28}$ In another study, bipolar patients in depressed and hypomanic stages of illness exhibited increased cortisol secretion relative to healthy control subjects. ${ }^{39}$ Light exposure has also been associated with abnormal melatonin secretion patterns (eg, low melatonin levels) in patients with bipolar I disorder, suggesting an abnormality in their circadian rhythm system. ${ }^{28}$ Circadian genes such as CLOCK, TIMELESS, ARNTL2, and $D B P$ have also demonstrated an association with circadian phenotypes established in bipolar disorder. ${ }^{40}$ More recently, animal models with defective clock genes such as CLOCK and Nrld1 have supplied new insight into the molecular pathways that underlie both mood dysfunctions and sleep disturbances. Findings suggest that mice with an altered $C L O C K$ gene (eg, a deletion of exon 19) demonstrate maniclike behaviors, increased hyperactivity, reduced need for sleep, and heightened reward-seeking behaviors. ${ }^{41,42}$ Further study of the CLOCK gene will supply increased insight into the associations linking circadian disruptions, mood disturbances, and abnormal sleep patterns. In addition, the Rev-erbalpha protein, which is encoded by the Nr1d1 gene, serves an important role in circadian rhythm regulation and generation. ${ }^{43}$ Mang et $\mathrm{al}^{43}$ examined electroencephalography (EEG) data in Rev-erbalpha knockout (KO) and wild-type mice during baseline, sleep deprivation, and recovery with cortical gene expression postsleep deprivation compared to baseline values. Findings indicated that a lack of Rev-erbalpha had an impact on the $\mathrm{KO}$ mice's homeostatic regulation of sleep; specifically, the KO mice demonstrated reduced EEG delta power and a smaller increase in sleep consolidation after baseline sleep onset and sleep deprivation, suggestive of a slower increase in homeostatic sleep need in periods of wakefulness. ${ }^{43} \mathrm{KO}$ mice also demonstrated increased theta activity during wakefulness, which predicted delta power in nonrapid eye movement sleep; these data are reflective of the EEG changes present in mood disorders. ${ }^{43}$ Future studies should continue to explore the role of Rev-erbalpha on mood regulation and homeostatic regulation of sleep. Finally, pharmacotherapy for bipolar disorder may also positively influence abnormal circadian rhythms; for instance, lithium has shown effectiveness in correcting an abnormal circadian cycle length. ${ }^{44}$

Alterations in the SCN in both cellular and physiological domains may relate to bipolar disorders. As discussed 
earlier, the SCN serves an important role in maintaining circadian rhythm function by integrating photic and nonphotic inputs. ${ }^{27}$ Among bipolar patients, alterations in the SCN may contribute to circadian rhythms that are out of phase or of low amplitude, ${ }^{45}$ such abnormalities may result from effects on neurotransmitters. ${ }^{46}$ One study found alterations in arginine vasopressin (AVP) neurons within the SCN of depressed patients; specifically, study patients demonstrated an increase in AVP-immunoreactive neurons and a decrease in AVP-messenger RNA neurons. More broadly, these data suggest a pattern of reduced synthesis and release of AVP in depression. ${ }^{47}$ Such findings may also have important implications for alterations in the SCN within bipolar patients. On a physiological level, early studies demonstrated that lesions in the SCN contribute to loss of circadian rhythms, thereby highlighting the role of the SCN in circadian system regulation and in maintenance of the temporal order of physiological processes. Specifically, alterations in the SCN may affect the ability of this region to coordinate temporal order of all cells, organs, and peripheral clocks. Failed temporal order can, in turn, lead to disrupted circadian rhythms. ${ }^{48-50}$ Indeed, failed coordination across the SCN, the peripheral clocks, and environmental variables may importantly contribute to bipolar illness. A lack of synchronization between the SCN and the peripheral clocks contributes to internal desynchronization, which can cause physiological responses to occur at incorrect times, thereby lead to mood episodes. ${ }^{48}$ In addition, the SCN and peripheral clocks rely on zeitgebers for entrainment of circadian rhythms. An absence of zeitgebers or a failure of zeitgebers to act on the correct receptors for both the SCN and the peripheral clocks can lead to desynchronized circadian rhythms. ${ }^{45}$

The social zeitgeber theory highlights the importance of circadian dysfunction in bipolar disorder. According to this theory, disruptions in biological rhythms may be caused by disturbances in a given individual's social routine and patterns leading to depression, with accumulating evidence that these circadian rhythm disruptions may trigger mania as well. ${ }^{21}$ Thus, sleep may serve as the most robust marker of the impact of the disrupted circadian rhythm system on mood.

\section{Sleep-wake rhythms as biomarkers of bipolar disorder Sleep in unipolar depression}

Most sleep studies for bipolar disorder have compared sleep irregularities in this population to individuals with unipolar depression (or individuals who do not experience mania or hypomania). Thus, we begin with understanding sleep in unipolar depression or a reduction in slow wave sleep, rapid eye movement (REM) sleep disinhibition, time between sleep onset and the occurrence of the first REM period, and increased REM density and disruptions in sleep continuity. ${ }^{51}$ Some studies have found that, in unipolar depression, the circadian rhythms of REM sleep seem to be shifted earlier or phase advanced. This finding demonstrated early support from Wehr et $\mathrm{al}^{52}$ who cited an antidepressant effect of a shifted sleep period for participants who went to sleep and woke up earlier than usual. Total sleep deprivation has also been found to enhance mood in $\sim 60 \%$ of patients with depression; however, in some cases, this deprivation has been linked to a subsequent depressive episode relapse on the following night. ${ }^{53,54}$ Berger et $\mathrm{al}^{55}$ explored the effect of combining total sleep deprivation with consecutive sleep phase advance therapy for a 1-week period to prevent the depressive relapse that tends to follow the antidepressant effect of total sleep deprivation. These investigators found that $61 \%$ of patients who experienced improvements in depressive symptomatology following total sleep deprivation maintained these improvements during sleep phase advance therapy. ${ }^{55}$

The literature also suggests that phase-delayed circadian misalignment is common in unipolar depression. ${ }^{56-58}$ Overall, studies in unipolar depression have not consistently found circadian rhythms to be either phase advanced or phase delayed. ${ }^{56,59} \mathrm{It}$ is thus important to consider the effect of all types of circadian misalignment on the course of depressive illness.

\section{Sleep in bipolar depression}

Analyses of polysomnography studies in unipolar depression compared to bipolar depression have specifically focused on the overlap in sleep disturbance symptoms between the two conditions. $^{37,51}$ Compared to unipolar depressed patients, depressed bipolar patients demonstrate heightened fragmentation of REM sleep (especially in bipolar I patients), longer sleep onset latency, a pattern toward an increased number of spindles, a greater percentage of awakenings, and greater REM density. ${ }^{60-64}$ Compared to healthy individuals, depressed bipolar patients demonstrate reduced REM latency, increased REM density, low sleep continuity, and extended slow-wave sleep latency; ${ }^{62,65-68}$ refer to Harvey ${ }^{20}$ for a full review. Relative to sleep in unipolar depression, sleep in bipolar depression is associated with a greater amount of eveningness preference $^{69,70}$ and a larger number of delayed sleep phase cases relative to unipolar depression. ${ }^{71}$

Bipolar patients may respond better to sleep deprivation than unipolar patients. ${ }^{13}$ Bipolar patients have a mismatched 
biological clock and sleep-wake cycle; sleep deprivation helps to correct this mismatch by enhancing sleep-wake homeostasis (process S) so as to balance the increased arousal of the depressed stage. ${ }^{20}$ Between $40 \%$ to $60 \%$ of bipolar patients with depression demonstrate improvements in mood following sleep deprivation. ${ }^{72}$

Plante and Winkelman ${ }^{13}$ note that sleep deprivation could be problematic for individuals with bipolar disorder, given its association with depression relapse following recovery sleep. In addition, sleep deprivation may be associated with the occurrence of a mood episode within the opposite pole. Among 206 bipolar depressed patients who received three cycles of sleep deprivation treatment, Colombo et $\mathrm{al}^{73}$ noted that $4.85 \%$ of participants exhibited a switch into mania and $5.83 \%$ of participants exhibited a switch into hypomania. When given in conjunction with lithium, sleep deprivation may be the most beneficial as lithium is effective in correcting an abnormal circadian system in some bipolar patients and may improve sleep deprivation treatment response. ${ }^{13}$ Sleep deprivation plus bright light therapy, ${ }^{74}$ or phase shift of the sleep period, may also help maintain the treatment effects of sleep deprivation. ${ }^{13}$ It should be noted that a certain genetic variant may predispose some patients with bipolar depression to respond better to the sleep deprivation treatment; specifically, Benedetti et $\mathrm{al}^{75}$ found that individuals who were homozygous for the long variant of the serotonin transporter gene 5-HTTLPR showed better mood improvements following sleep deprivation than individuals who were homozygous or heterozygous for the short variant.

\section{Sleep in mania}

Reduced need for sleep is a Diagnostic and Statistical Manual of Mental Disorders, Fifth Edition diagnostic criterion for mania and also serves as a marker for the association between mania and sleep disturbances. Self-report of decreased need for sleep is highly common during acute mania ${ }^{37}$ and is verified through polysomnography data. In an interesting early finding, Hudson et $\mathrm{al}^{76}$ found significant similarities between sleep disturbances in unipolar depression and in acute mania among age-matched manic patients and depressed patients with both groups of participants demonstrating disrupted sleep continuity, reduced REM latency, heightened percentage of stage I sleep, and increased REM density relative to age-matched controls. This finding suggests that sleep disturbances within mania and depression result from similar processes. ${ }^{76}$ Other studies have found a shorter total sleep time and a greater time awake in bed among manic patients (for a review, see Plante et $\mathrm{al}^{13}$ ). It should be noted that reduced sleep in manic patients may not result from a decreased need for sleep, but instead serve as a byproduct of the overall hyperactivity that characterizes the manic phase. ${ }^{37}$ In many cases, sleep reduction may be an important factor leading to a manic episode. As discussed earlier, Colombo et $\mathrm{al}^{73}$ found that sleep deprivation as a treatment for bipolar depression resulted in a switch to mania or hypomania for a percentage of the study sample. These findings were also supported by Wehr et $\mathrm{al}^{77}$ who found that seven of nine patients deprived of sleep for one night experienced subsequent mania or hypomania. Wehr et al ${ }^{78}$ posit that sleep deprivation is the "final common pathway" to the experience of mania. Several factors contribute to reduced sleep, which in turn leads to symptoms of hypomania or mania. This contributes to an ongoing cycle as, once the individual is in a manic or hypomanic state, a pattern of reduced sleep is maintained. ${ }^{78}$

\section{Sleep in euthymia}

Euthymia has been conceptualized as the remitted time between episodes, but often symptoms persist between episodes. For example, $\sim 70 \%$ of bipolar patients continue to experience sleep disturbance even during euthymia. ${ }^{79}$ One meta-analysis of several studies found that, compared to healthy controls, bipolar individuals during euthymia demonstrate significantly longer total sleep time and time in bed. Also, during this phase of the condition, there was significant variability in total sleep time. ${ }^{80}$ Several studies have found that bipolar patients when euthymic also demonstrate longer sleep-onset latency, increased awakenings during the night, increased REM density, and reduced sleep efficiency. ${ }^{79,81}$

\section{Sleep in bipolar disorder: relevance and clinical implications}

This review highlights the role that sleep has in the etiology and maintenance of mood episodes for individuals with bipolar disorder. This lends support for sleep disturbance to be an important target of research and intervention, especially given data that sleep disturbances in bipolar disorder are also associated with heightened medical burden through conditions such as CVD, increased weight, and diabetes mellitus ${ }^{12,37}$ with recent studies highlighting the circadian rhythm system as an important factor contributing to the association between sleep disturbances and CVD (eg, influence of meal timing on insulin resistance and a risk factor for diabetes and CVD). ${ }^{37}$ Sleep deprivation may also be associated with poor eating habits in bipolar patients, given the association of sleep deprivation with certain hormonally influenced 
responses that lead to enhanced caloric intake. ${ }^{12}$ Further, sleep disturbances in bipolar disorder are linked to reduced energy levels and thus, a lessened likelihood of engaging in other healthy behaviors (eg, seeing others, grocery shopping, cooking, and exercising). ${ }^{12}$ Finally, sleep disturbances are linked to increased risk for suicidal ideation and suicide attempts among bipolar patients. ${ }^{82}$ These data highlight the many possible clinical implications of improving sleep in bipolar disorder.

Sleep disturbances in bipolar disorder may also be an important marker for relapse. Sleep disruption is common to the euthymic phase of bipolar disorder with studies citing the association of poor sleep and cognitive functioning with low work performance in euthymic patients, ${ }^{83}$ increased use of sleep medication, reduced daytime functioning, longer sleep latency, ${ }^{84}$ and mood episode recurrence. ${ }^{9}$ One study found poor sleep to predict earlier mood episode recurrence independent of any residual mood symptoms. Further, Harvey et $\mathrm{al}^{85}$ found that euthymic bipolar patients demonstrated clinically significant sleep disturbances, reduced sleep efficiency, low activity levels during the day, and heightened fear and anxiety about not sleeping well. Given that sleep disturbances are common in euthymic bipolar patients and associated with mood episode recurrence, further study of the role of sleep disturbances in bipolar episode relapse is vital.

\section{Conclusion and future directions}

Sleep appears to be a likely biomarker of bipolar disorder, given that sleep disturbances persist across the phases of the condition (depressive, manic, and euthymic) and leads to worse course of illness. Further evidence of sleep as a biomarker is drawn from the evidence of other circadian rhythm disruptions in bipolar disorder and their effect on the condition as well as evidence that sleep manipulations can affect the course of the illness. Given the impact of sleep disturbances on bipolar disorder, future research would benefit from examining novel psychosocial, pharmacological, and technological strategies to improve sleep. Zachariae et $\mathrm{al}^{86}$ conducted a meta-analysis of Internet-delivered cognitive behavioral therapy for insomnia (eCBT-I) with findings indicating that eCBT-I was effective in improving self-reported sleep quality, sleep onset latency, sleep efficiency, and total sleep time among individuals with insomnia or self-reported sleep problems. ${ }^{86}$ An eCBT-I approach warrants further attention in a bipolar sample. Harvey et $\mathrm{al}^{11}$ developed a cognitive behavioral therapy for insomnia specific to bipolar disorder and compared this intervention to a psychoeducational control group. They found that cognitive behavioral therapy for insomnia specific to bipolar disorder lowered overall rate of mood episode relapse, rate of hypomania/mania relapse, days in a bipolar episode, and lowered insomnia severity compared to the control group. ${ }^{11}$ Sylvia et $\mathrm{al}^{87}$ examined an electrocardiogram-based home sleep monitoring device (M1) in bipolar patients and found it to improve participants' overall sleep duration. These investigators are currently exploring the application of the M1 device in a study of cognitive behavioral therapy for sleep problems in bipolar disorder. Another recent advance in the study of sleep and bipolar disorder is the application of mindfulness-based cognitive therapy for insomnia. ${ }^{88,89}$ Preliminary data suggest that mindfulness could be a helpful adjunct treatment for sleep. Indeed, an integrated approach may yield the best findings for informing future treatments for individuals with sleep disturbances in bipolar disorder.

\section{Disclosure}

Doctor Sylvia was a shareholder in Concordant Rater Systems and has served in the past year as a consultant for United Biosource Corporation, Clintara, Bracket, and Clinical Trials Network and Institute. She receives royalties from New Harbinger and has received grant/research support from NIMH, PCORI, AFSP, and Takeda. The other author reports no conflicts of interest in this work.

\section{References}

1. Merikangas KR, Akiskal HS, Angst J, et al. Lifetime and 12-month prevalence of bipolar spectrum disorder in the national comorbidity survey replication. Arch Gen Psychiatry. 2007;64(5):543-552.

2. APA. Diagnostic and Statistical Manual of Mental Disorders. 5th ed. Arlington, VA: American Psychiatric Association; 2013.

3. Woods SW. The economic burden of bipolar disease. J Clin Psychiatry. 2000;61(suppl 13):38-41.

4. Ösby U, Brandt L, Correia N, Ekbom A, Sparén P. Excess mortality in bipolar and unipolar disorder in Sweden. Arch Gen Psychiatry. 2001;58(9):844-850.

5. Crump C, Sundquist K, Winkleby MA, Sundquist J. Comorbidities and mortality in bipolar disorder: a Swedish national cohort study. JAMA Psychiatry. 2013;70(9):931-939.

6. Weber NS, Fisher JA, Cowan DN, Niebuhr DW. Psychiatric and general medical conditions comorbid with bipolar disorder in the National Hospital Discharge Survey. Psychiatr Services. 2011;62: 1152-1158.

7. Deckersbach T, Peters AT, Sylvia L, et al. Do comorbid anxiety disorders moderate the effects of psychotherapy for bipolar disorder? Results from STEP-BD. Am J Psychiatry. 2014;171(2):178-186.

8. Vojta C, Kinosian B, Glick H, Altshuler L, Bauer MS. Self-reported quality of life across mood states in bipolar disorder. Compr. Psychiatry. 2001;42(3):190-195.

9. Sylvia LG, Dupuy JM, Ostacher MJ, et al. Sleep disturbance in euthymic bipolar patients. J Psychopharmacol. 2012;26(8):1108-1112.

10. Giglio LMF, Magalhães PV, Andersen ML, Walz JC, Jakobson L, Kapczinski F. Circadian preference in bipolar disorder. Sleep Breath. 2010;14(2):153-155.

11. Harvey AG, Soehner AM, Kaplan KA, et al. Treating insomnia improves mood state, sleep, and functioning in bipolar disorder: a pilot randomized controlled trial. J Consult Clin Psychol. 2015;83(3):564. 
12. Harvey AG, Talbot LS, Gershon A. Sleep disturbance in bipolar disorder across the lifespan. Clin Psychol SciPract. 2009;16(2):256-277.

13. Plante DT, Winkelman JW. Sleep disturbance in bipolar disorder: therapeutic implications. Am J Psychiatry. 2008;165(7):830-843.

14. Steinan M, Scott J, Lagerberg T, et al. Sleep problems in bipolar disorders: more than just insomnia. Acta Psychiatr Scand. 2016;133(5):368-377.

15. Robillard R, Naismith SL, Hickie IB. Recent advances in sleep-wake cycle and biological rhythms in bipolar disorder. Curr Psychiatry Rep. 2013;15(10):1-10.

16. Kaplan K, McGlinchey E, Soehner A, et al. Hypersomnia subtypes, sleep and relapse in bipolar disorder. Psychol Med. 2015;45(08):1751-1763.

17. Jackson A, Cavanagh J, Scott J. A systematic review of manic and depressive prodromes. J Affect Disord. 2003;74(3):209-217.

18. Sierra P, Livianos L, Arques S, Castelló J, Rojo L. Prodromal symptoms to relapse in bipolar disorder. Aust NZJ Psychiatry. 2007;41(5):385-391.

19. Yildiz A, Ruiz P, Nemeroff C. Bipolar Book: History. Neurobiology, and Treatment. New York: Oxford University Press; 2015.

20. Harvey AG. Sleep and circadian rhythms in bipolar disorder: seeking synchrony, harmony, and regulation. Am J Psychiatry. 2008;165(7): 820-829.

21. Grandin LD, Alloy LB, Abramson LY. The social zeitgeber theory, circadian rhythms, and mood disorders: review and evaluation. Clin Psychol Rev. 2006;26(6):679-694.

22. Mansour HA, Monk TH, Nimgaonkar VL. Circadian genes and bipolar disorder. Ann Med. 2005;37(3):196-205.

23. Rosenwasser AM, Turek FW. Neurobiology of circadian rhythm regulation. Sleep Med Clin. 2015;10(4):403-412.

24. Ehlers CL, Frank E, Kupfer DJ. Social zeitgebers and biological rhythms: a unified approach to understanding the etiology of depression. Arch Gen Psychiatry. 1988;45(10):948-952.

25. Zee PC, Attarian H, Videnovic A. Circadian rhythm abnormalities. Continuum (Minneap Minn). 2013;19(1 Sleep Disorders):132.

26. Alloy LB, Nusslock R, Boland EM. The development and course of bipolar spectrum disorders: an integrated reward and circadian rhythm dysregulation model. Annu Rev Clin Psychol. 2015;11:213-250.

27. Cermakian N, Boivin DB. A molecular perspective of human circadian rhythm disorders. Brain Res Brain Res Rev. 2003;42(3):204-220.

28. Nurnberger JI, Adkins S, Lahiri DK, et al. Melatonin suppression by light in euthymic bipolar and unipolar patients. Arch Gen Psychiatry. 2000;57(6):572-579.

29. Weitzman ED, Zimmerman JC, Czeisler CA, Ronda J. Cortisol secretion is inhibited during sleep in normal man. J Clin Endocrinol Metab. 1983;56(2):352-358.

30. Hickie IB, Naismith SL, Robillard R, Scott EM, Hermens DF. Manipulating the sleep-wake cycle and circadian rhythms to improve clinical management of major depression. BMC Med. 2013;11(1):79.

31. Soares JC, Young AH. Bipolar Disorders: Basic Mechanisms and Therapeutic Implications. Boca Raton: CRC Press; 2007.

32. Achermann P. The two-process model of sleep regulation revisited. Aviat Space Environ Med. 2004;75(3):A37-A43.

33. Kryger MH, Roth T, Dement WC. Principles and Practice of Sleep Medicine. Philadelphia: Saunders; 2010.

34. Becker KL, editor. Principles and Practice of Endocrinology and Metabolism. 3rd ed. Philadelphia: Lippincott Williams \& Wilkins; 2001.

35. Reichert CF, Maire M, Schmidt C, Cajochen C. Sleep-wake regulation and its impact on working memory performance: the role of adenosine. Biology (Basel). 2016;5(1):1-25.

36. Singh I, Rose N. Biomarkers in psychiatry. Nature. 2009;460(7252): 202-207.

37. Soreca I. Circadian rhythms and sleep in bipolar disorder: implications for pathophysiology and treatment. Curr Opin Psychiatry. 2014;27(6):467-471.

38. Malkoff-Schwartz S, Frank E, Anderson B, et al. Stressful life events and social rhythm disruption in the onset of manic and depressive bipolar episodes: a preliminary investigation. Arch Gen Psychiatry. 1998;55(8):702-707.
39. Cervantes P, Gelber S, Kin FN, Nair VN, Schwartz G. Circadian secretion of cortisol in bipolar disorder. J Psychiatry Neurosci. 2001;26(5):411-416.

40. Shi J, Wittke-Thompson JK, Badner JA, et al. Clock genes may influence bipolar disorder susceptibility and dysfunctional circadian rhythm. Am J Med Genet B. 2008;147(7):1047-1055.

41. Roybal K, Theobold D, Graham A, et al. Mania-like behavior induced by disruption of CLOCK. Proc Natl Acad Sci USA. 2007;104(15): 6406-6411.

42. Landgraf D, McCarthy MJ, Welsh DK. The role of the circadian clock in animal models of mood disorders. Behav Neurosci. 2014;128(3):344-359.

43. Mang GM, La Spada F, EmmeneggerY, et al. Altered sleep homeostasis in rev-erbo knockout mice. Sleep. 2016;39(3):589-601.

44. Abe M, Herzog ED, Block GD. Lithium lengthens the circadian period of individual suprachiasmatic nucleus neurons. Neuroreport. 2000;11(14):3261-3264.

45. Wirz-Justice A, Bromundt V, Cajochen C. Circadian disruption and psychiatric disorders: the importance of entrainment. Sleep Med Clin. 2009;4:273-284.

46. Schlaepfer TE, Nemeroff CB. Neurobiology of Psychiatric Disorders. Amsterdam: Elsevier; 2012.

47. Zhou JN, Riemersma RF, Unmehopa UA, et al. Alterations in arginine vasopressin neurons in the suprachiasmatic nucleus in depression. Arch Gen Psychiatry. 2001;58(7):655-662.

48. Salgado-Delgado R, Osorio AT, Saderi N, Escobar C. Disruption of circadian rhythms: a crucial factor in the etiology of depression. Depress Res Treat. 2011;2011:839743.

49. Stephan FK, Zucker I. Circadian rhythms in drinking behavior and locomotor activity of rats are eliminated by hypothalamic lesions. Proc Natl Acad Sci USA. 1972;69(6):1583-1586.

50. Moore RY, Eichler VB. Loss of a circadian adrenal corticosterone rhythm following suprachiasmatic lesions in the rat. Brain Res. 1972;42(1):201-206.

51. Voderholzer U, Weske G, Ecker S, Riemann D, Gann H, Berger M. Neurobiological findings before and during successful lithium therapy of a patient with 48-hour rapid-cycling bipolar disorder. Neuropsychobiology. 2002;45(suppl 1):13-19.

52. Wehr TA, Wirz-Justice A, Goodwin FK, Duncan W, Gillin JC. Phase advance of the circadian sleep-wake cycle as an antidepressant. Science. 1979;206(4419):710-713.

53. Wu JC, Bunney WE. The biological basis of an antidepressant response to sleep deprivation and relapse: review and hypothesis. Am J Psychiatry. 1990;147(1):14-21.

54. Wirz-Justice A, Van den Hoofdakker RH. Sleep deprivation in depression: what do we know, where do we go? Biol Psychiatry. 1999;46(4):445-453.

55. Berger M, Vollmann J, Hohagen F, et al. Sleep deprivation combined with consecutive sleep phase advance as a fast-acting therapy in depression: an open pilot trial in medicated and unmedicated patients. $A m J$ Psychiatry. 1997;154(6):870-872.

56. Emens J, Lewy A, Kinzie JM, Arntz D, Rough J. Circadian misalignment in major depressive disorder. Psychiatry Res. 2009;168(3):259-261.

57. Guzel Ozdemir P, Boysan M, Smolensky MH, Selvi Y, Aydin A, Yilmaz E. Comparison of venlafaxine alone versus venlafaxine plus bright light therapy combination for severe major depressive disorder. J Clin Psychiatry. 2015;76(5):e645-e654.

58. Lewy AJ. Circadian misalignment in mood disturbances. Curr Psychiatry Rep. 2009;11(6):459-465.

59. Van den Hoofdakker RH. Chronobiological theories of nonseasonal affective disorders and their implications for treatment. J Biol Rhythms. 1994;9(2):157-183.

60. de Maertelaer V, Hoffman G, Lemaire M, Mendlewicz J. Sleep spindle activity changes in patients with affective disorders. Sleep. 1987;10(5):443-451. 
61. Fossion P, Staner L, Dramaix M, et al. Does sleep EEG data distinguish between UP, BPI, or BPII major depressions? An age and gender controlled study. J Affect Disord. 1998;49(3):181-187.

62. Duncan WC Jr, Pettigrew KD, Gillin JC. REM architecture changes in bipolar and unipolar depression. Am J Psychiatry. 1979;136(11):1424-1427.

63. Giles DE, Rush AJ, Roffwarg HP. Sleep parameters in bipolar I, bipolar II and unipolar depressions. Biol Psychiatry. 1986;21(13): 1340-1343.

64. Riemann D, Voderholzer U, Berger M. Sleep and sleep-wake manipulations in bipolar depression. Neuropsychobiology. 2002;45(suppl 1):7-12.

65. Lauer CJ, Wiegand M, Krieg JC. All-night electroencephalographic sleep and cranial computed tomography in depression: a study of unipolar and bipolar patients. Eur Arch Psychiatry Clin Neurosci. 1992;242(2-3):59-68.

66. Gillin JC, Duncan W, Pettigrew KD, Frankel BL, Snyder F. Successful separation of depressed, normal, and insomniac subjects by EEG sleep data. Arch Gen Psychiatry. 1979;36(1):85-90.

67. Thase ME, Himmelhoch JM, Mallinger AG, Jarrett DB, Kupfer DJ. Sleep EEG and DST findings in anergic bipolar depression. Am J Psychiatry. 1989;146(3):329-333.

68. Jernajczyk W. Latency of eye movement and other REM sleep parameters in bipolar depression. Biol Psychiatry. 1986;21(5-6):465-472.

69. Wood J, Birmaher B, Axelson D, et al. Replicable differences in preferred circadian phase between bipolar disorder patients and control individuals. Psychiatry Res. 2009;166(2-3):201-209.

70. Mansour H, Wood J, Logue T, et al. Circadian phase variation in Bipolar I Disorder. Chronobiol Int. 2005;22(3):571-584.

71. Robillard R, Naismith SL, Rogers NL, et al. Delayed sleep phase in young people with unipolar or bipolar affective disorders. $J$ Affect Disord. 2013;145(2):260-263.

72. Barbini B, Colombo C, Benedetti F, Campori E, Bellodi L, Smeraldi E. The unipolar-bipolar dichotomy and the response to sleep deprivation. Psychiatry Res. 1998;79(1):43-50.

73. Colombo C, Benedetti F, Barbini B, Campori E, Smeraldi E. Rate of switch from depression into mania after therapeutic sleep deprivation in bipolar depression. Psychiatry Res. 1999;86(3):267-270.

74. Vai B, Poletti S, Radaelli D, et al. Successful antidepressant chronotherapeutics enhance fronto-limbic neural responses and connectivity in bipolar depression. Psychiatry Res. 2015;233(2):243-253.

75. Benedetti F, Serretti A, Colombo C, et al. Influence of a functional polymorphism within the promoter of the serotonin transporter gene on the effects of total sleep deprivation in bipolar depression. Am J Psychiatry. 1999;156(9):1450-1452.
76. Hudson JI, Lipinski JF, Keck PE, et al. Polysomnographic characteristics of young manic patients: comparison with unipolar depressed patients and normal control subjects. Arch Gen Psychiatry. 1992;49(5):378-383.

77. Wehr TA, Goodwin FK, Wirz-Justice A, Breitmaier J, Craig C. 48-hour sleep-wake cycles in manic-depressive illness: naturalistic observations and sleep deprivation experiments. Arch Gen Psychiatry. 1982;39(5):559-565.

78. Wehr TA, Sack DA, Rosenthal NE. Sleep reduction as a final common pathway in the genesis of mania. Am J Psychiatry. 1987;144(2): 201-204.

79. Soehner AM, Kaplan KA, Harvey AG. Insomnia comorbid to severe psychiatric illness. Sleep Med Clin. 2013;8(3):361-371.

80. Ng TH, Chung K-F, Ho FY-Y, Yeung W-F, Yung K-P, Lam T-H. Sleep-wake disturbance in interepisode bipolar disorder and high-risk individuals: a systematic review and meta-analysis. Sleep Med Rev. 2015;20: $46-58$.

81. Edinger JD. Insomnia. Sleep Med Clin. 2013;8(3):xv-xvi.

82. Lai Y-C, Huang M-C, Chen H-C, et al. Familiality and clinical outcomes of sleep disturbances in major depressive and bipolar disorders. $J$ Psychosom Res. 2014;76(1):61-67.

83. Boland EM, Stange JP, Molz Adams A, et al. Associations between sleep disturbance, cognitive functioning and work disability in Bipolar Disorder. Psychiatry Res. 2015;230(2):567-574.

84. Cretu JB, Culver JL, Goffin KC, Shah S, Ketter TA. Sleep, residual mood symptoms, and time to relapse in recovered patients with bipolar disorder. J Affect Disord. 2016;190:162-166.

85. Harvey AG, Schmidt DA, Scarna A, Semler CN, Goodwin GM. Sleeprelated functioning in euthymic patients with bipolar disorder, patients with insomnia, and subjects without sleep problems. Am J Psychiatry. 2005;162(1):50-57.

86. Zachariae R, Lyby MS, Ritterband LM, O'Toole MS. Efficacy of internet-delivered cognitive-behavioral therapy for insomnia - a systematic review and meta-analysis of randomized controlled trials. Sleep Med Rev. 2016;30:1-10.

87. Sylvia LG, Salcedo S, Bianchi MT, Urdahl AK, Nierenberg AA, Deckersbach T. A novel home sleep monitoring device and brief sleep intervention for bipolar disorder: feasibility, tolerability, and preliminary effectiveness. Cognit Ther Res. 2014;38(1):55-61.

88. Deckersbach T, Hölzel BK, Eisner LR, et al. Mindfulness-based cognitive therapy for nonremitted patients with bipolar disorder. CNS Neurosci Ther. 2012;18(2):133-141.

89. Deckersbach T, Hölzel B, Eisner L, Lazar SW, Nierenberg AA. Mindfulness-Based Cognitive Therapy for Bipolar Disorder. New York: Guildford Press; 2014.
Nature and Science of Sleep

\section{Publish your work in this journal}

Nature and Science of Sleep is an international, peer-reviewed, open access journal covering all aspects of sleep science and sleep medicine, including the neurophysiology and functions of sleep, the genetics of sleep, sleep and society, biological rhythms, dreaming, sleep disorders and therapy, and strategies to optimize healthy sleep. The manuscript

\section{Dovepress}

management system is completely online and includes a very quick and fair peer-review system, which is all easy to use. Visit http://www. dovepress.com/testimonials.php to read real quotes from published authors. 